\title{
Public Spaces as an Invaluable Resource for Delivering Healthy and More Equitable Cities and Communities
}

\author{
Jose Chong, Sohel Rana, Mark Ojal \\ UN-Habitat, Kenya \\ jose.chong@un.org | sohel.rana@un.org | mark.ojal@un.org
}

\begin{abstract}
The state of our cities and towns is a significant determining factor of the health and wellbeing of most of the world's population in the twenty-first century. Cities and towns have become the epicentre of the COVID-19 pandemic. The pandemic has put to test the current urban development model including mobility, urban form, urban food systems and local economy. Cumulative social, economic and environmental inequalities reinforced by chronic spatial injustice have shaped exposure, vulnerability and ultimately, the risk and outcome of non-communicable, and infectious diseases. In the same context, green and public spaces have emerged as an infrastructure of opportunity to build back better, especially in low income and minority communities. This article looks at the impacts, responses and pathways for future-proofing cities and human settlements through green, and public spaces.
\end{abstract}

Keywords: healthy cites, equitable cities, COVID-19, green public spaces

To cite this article:

Chong, J., Rana, S., Ojal, M. (2020). Public Spaces as an Invaluable Resource for Delivering Healthy and More Equitable Cities and Communities, The Journal of Public Space, 5(3), 227-232, DOI I0.3289I/jps.v5i3.I4I5

This article has been double blind peer reviewed and accepted for publication in The Journal of Public Space.

(c) (1) (5) This work is licensed under a Creative Commons Attribution - Non Commercial 4.0

International License https://creativecommons.org/licenses/by-nc/4.0/ 


\section{Introduction}

Urban health and wellbeing are becoming increasingly dominant urban problems in both developed and developing countries (Perdue, Stone, \& Gostine, 2003). The state of our cities and towns is a significant determining factor of the health and wellbeing of most of the world's population in the twenty-first century. 54 percent lives in urban areas, and this is projected to rise to six out of every 10 people by 2030 (UNDESA, 2014). Today, rates of non-communicable diseases (NCDs), infectious diseases, and mental illness are higher in cities compared to rural areas. The global economic impact of the five leading NCDs cardiovascular disease, chronic respiratory disease, cancer, diabetes and mental illness could total US $\$ 47$ trillion over the next 20 years (RTPI, 20I4). Moreover, cities and towns have become the epicentre of the COVID-19 pandemic, accounting for over 90 percent of the confirmed cases (United Nations, 2020; UN-HABITAT, UNCDF, UCLG-Africa, UNECA, 2020).

The pandemic found many cities and countries unprepared despite many warnings and recent epidemics such as Ebola and Severe Acute Respiratory Syndrome (SARS) (UNHabitat; UNDRR, 2020). It has challenged the current urban development model including mobility, urban form, urban food systems and local economy. Cumulative social, economic and environmental inequalities reinforced by chronic spatial injustice have shaped exposure, vulnerability and ultimately, the risk and outcome of non-communicable, and infectious diseases. The pandemic has exposed stark inequalities in accessibility to risk-reducing infrastructure and services, shining light on disparities in accessibility, quality and distribution of green and public spaces across the urban divide. In the same context, green and public spaces have emerged as basic risk-reducing infrastructure, an essential urban service, an infrastructure of opportunity to build back better, especially in low income and minority communities, an important 'third place' (Oldenburg R. , 1989; Oldenburg \& Brissett, 1982), especially in times of crisis.

The quest for healthier cities and towns is therefore an urgent development agenda. Urban development decision makers, the built environment and the scientific communities, the private sector and the civil society must look for ways to develop cities as instruments of health and wellbeing. The COVID- 19 pandemic provides an opportunity to build back better, rethinking the city from the group-up, integrating spatial and environmental justice in urban regeneration endeavours including mobility and accessibility of green, and public spaces. This article looks at the impacts, practices and pathways for future-proofing cities and human settlements through green, and public spaces.

\section{Public spaces in the face of unprecedented crises}

Well designed and well managed public spaces such as parks and gardens, urban forests, nature reserves, playgrounds, greenways, markets and streets make direct contributions to urban health and wellbeing, ensuring healthy living and longer life. When provided in adequate quantity across the urban divide, high quality of green, and public spaces support ecosystem services such as clean water, purifying air, enhancing and protecting biodiversity, cooling our cities, storing carbon, and protecting the earth natural features and processes (Prospero, 20I0). They are a critical risk-reducing infrastructure, and provide storm-water attenuation, contributing to flood management. They also provide opportunities for active and passive recreation, active mobility including cycling and walking, a natural relief from the 
hustle and bustle of the city, and social interaction, consequently promoting better health outcomes.

The counter-pandemic measures like lockdowns, isolation, physical distancing and 'stay home' advisory are also leading to some unintended consequences like increasing genderbased violence, violence against children and loneliness (UN Women, 2020). The pandemic has challenged the uses, roles of and perceptions towards public space; roles and capacity of urban development actors; the place of public, and non-motorised transport; planning of green, and public spaces; regulations for use of public spaces; and the $21^{\text {st }}$ century urban model (Honey-Rosés, et al., 2020). Similarly, it has also helped city leaders realize the extended and alternative uses of public spaces to respond to urban risks, highlighting the need for short, medium and long-term strategies. Streets and public open spaces have been adapted as alternative medical facilities, public markets, community gardens and places for walking and cycling.

Globally, cities are reclaiming green, and public spaces, including parks and streets, and transforming them into people places. In Nairobi, the pandemic has sparked a green renaissance, leading to reclamation and revitalization of green, and public spaces. The influx of people into parks and urban forests in the city is a manifestation of the demand for these spaces and is also a wake-up call to improve the accessibility and distribution across the urban divide, providing public spaces such as parks, forests and playgrounds within neighborhoods. In Kibera, an informal settlement in Kenya, there are very few public spaces and lack of clean water and sanitation. During this time of the pandemic, public spaces have doubled up as hand-washing stations and as places to get information on COVID-19

prevention. They have also become places where vulnerable groups gather to receive relief support.

Besides recreational and ecological benefits, public spaces are also places where livelihoods thrive, women vend their produce and young people sell their art. Cities and local governments need to support these livelihoods, especially in rapidly urbanizing and resource poor cities where a large part of the population works in the informal sector earning a daily wage. In Kalaw, a small tourist town in Myanmar, officials have closed off some streets and converted them into vegetable markets to promote safe vending and grocery shopping. In Banjul, the Gambia, the city council is working on a public market decongestion plan to reduce the number of vendors and visitors using the city's main public market. In Kisumu, Kenya, the county government in collaboration with local youth has converted public open spaces into temporary open-air markets, decongesting the city's public markets to achieve physical distancing and adequate aeration. In Nairobi's Korogocho slums, local youth are integrating vertical gardens in public spaces, providing them with food and they sell excess produce.

These innovations and practices can help urban development decision-makers and practitioners to prepare for and adapt to a multiplicity of everyday risks and disasters. Creating a well-connected and integrated system of public open spaces and streets makes more liveable, lovable and resilient cities and neighbourhoods. This results into multiple cobenefits including better air quality, which also impacts general health and well-being in cities and human settlements. A holistic approach to planning should consider combining grey, green and blue infrastructure at different levels to support healthier cities and communities. 


\section{United Nations Development System and COVID-I 9 response and recovery}

The 2030 Agenda for Sustainable Development places premium on health and wellbeing and recognizes the role of good urban design in delivering better health outcomes. Goal 3 specifically calls for ensuring healthy lives for all and promoting wellbeing for all at all ages. This is further reinforced by target II.7 which recognizes creating safe, inclusive and accessible green, and public spaces as a lever for achieving sustainable cities and communities. Health and wellbeing of cities and communities has also been recognized as the pulse of the New Urban Agenda, underscoring the link between the quality of urban environment on one hand, and physical and mental health and wellbeing in cities and communities on the other (WHO and UN-Habitat, 2020).

The pandemic in the urban world presents a classic example of a tangled 'mess of thread' where it is difficult to determine which one to pull first. Overcrowding, concentrated poverty, inadequate water and sanitation, and solid waste management, poorly distributed risk-reducing infrastructure all make cities soft spots for diseases and disease-causing pathogens to thrive (Mukherjee \& Sen, 2020). In the wake of the devastation and disruption of lives and livelihoods in cities and communities, the United Nations released a five-point policy brief to guide governments, and development and humanitarian partners across all levels on how to reduce the impact of the pandemic on lives, livelihoods, and protect the most vulnerable. These include: ensuring that essential health services are available and health systems are protected; helping people cope with adversity, through social protection and basic services; protecting jobs, supporting small and medium-sized enterprises, and informal sector workers through economic response and recovery programmes; guiding the necessary surge in fiscal and financial stimulus to make macroeconomic policies work for the most vulnerable and strengthening multilateral and regional responses; and lastly, promoting social cohesion and investing in community-led resilience and response systems. Collectively, this set of policies attempt to 'untangle' the mess of thread by offering targeted entry-points. The policy brief recognizes the need to accelerate building resilient cities and communities.

Globally, the COVID-19 pandemic has exposed the fragility of our urban systems (UNHabitat, 2020). Structural intra-urban inequalities have been exacerbated by the pandemic and vulnerable populations including the low income and the urban poor have found it difficult to cope with the prevailing situation and adhere to the COVID- 19 control guidelines. It is for this reason that UN-Habitat is concentrating its efforts to mobilize human and financial resources to support local governments and communities affected by the pandemic. Experiences and innovations from the COVID pandemic demonstrate that stronger partnerships are needed to build safer, resilient and inclusive cities and communities. They also underscore the need for a shared policy agenda across the built environment community of practice, the scientific community, the business community and the civil society to work towards future-proofing cities and communities (UN-Habitat, 2020).

\section{Key recommendations on planning public spaces for healthy communities}

Based on the experience of the UN-Habitat's Global Public Space Programme and partners, there are inspiring practices from around the world, find below some key recommendations proposed to that link public space and health agendas (UN-Habitat, 2020). 
$\checkmark$ Design public spaces as flexible, multifunctional and adaptable.

They can provide space for emergency response during the pandemic (temporary health care facilities, medical supplies and food distribution). During the crisis, open spaces can also facilitate movements through non-motorized mobility alternatives, provide opportunities for physical outdoor activities and support livehood of economic vulnerable populations.

$\checkmark$ Design public spaces so that they can provide emergency services for the vulnerable and marginalized.

Well-planned and designed public space can provide the necessary public sanitation facilities during the crisis (bathrooms, water points, washing facilities). The availability of these public facilities is particular important and it is vital in informal settlements to keep daily hygiene practices.

$\checkmark$ Establish a well-connected, integrated and equitable system of public spaces.

Streets and open spaces system with enough space and greening which promotes cycling and walking. A well-designed and maintained public space network can contribute with the reduction of $\mathrm{CO} 2$ emissions and better air quality improving people's health and wellbeing.

$\checkmark$ Plan for the self-sufficient and compact neighbourhoods.

Allow that the residents can have all their needs met (work, school, shopping, health, leisure or culture) within 15 minutes from their own doorstep by foot, bike and/or public transport.

\section{Conclusions and way forward}

The common reference to green public spaces such as parks and gardens, urban forests, greenways and nature reserves among others with the physiological metaphor 'the lungs of the city' connotes the intricate relationship between urban planning and design, and health and wellbeing in cities. The COVID-19 pandemic has put the importance of access to green, and public spaces on the limelight. It has highlighted disparities in the supply and distribution of green, and public spaces across the urban divide, reinforcing existing structural inequalities regarding access.

Urban development decision makers and actors need to ensure that the planning system delivers a comprehensive network of green, and public spaces in cities and towns as an urgent global urban (re)development agenda. In addition, national and local governments need to step up action on disaster risk governance, and disaster risk-informed urban planning and development in order to prepare for, adapt to and build back better from urban risks such as pandemics. Importantly, governments and urban development actors need better granular data including new metrics for green, and public spaces, and health and wellbeing to inform better urban planning and design.

\section{References}

Honey-Rosés, J., Anguelovski, I., Chireh, V., Daher, C., Van den Bosch, C., Litt, J., Nieuwenhuijsen, M. (2020). The impact of COVID-I 9 on public space: an early review of the emerging questions - design, perceptions and inequities. Cities and Health. 
Public Spaces as an Invaluable Resource for Delivering Healthy and More Equitable Cities and Communities

Mahler, D. G., Lakner, C., Castaneda, A., \& Wu, H. (2020, June 08). World Bank Blogs. Retrieved from World Bank: https://blogs.worldbank.org/opendata/updated-estimates-impact-covid- I9global-poverty

Mukherjee, J., \& Sen, A. (2020, May 19). From SMART to sustainable cities: Is COVIDI9 an opportunity? Retrieved from Oberver Research Foundation: https://www.orfonline.org/expert-speak/fromsmart-to-sustainable-cities-is-covid I 9-an-opportunity-66363/

OECD. (2020, July 23). Cities Policy Responses . Retrieved from OECD Website: https://www.oecd.org/coronavirus/policy-responses/cities-policy-responses-fd I 053ff/

Oldenburg, R. (1989). The great good place. New York: Marlowe.

Oldenburg, R., \& Brissett, D. (1982). The third place . Qual Sociol, 265-284.

Perdue, W., Stone, L., \& Gostine, L. (2003). The Built Environment and Its Relationship to the Public's Health: The Legal Framework. Am J Public Health, 1390-1394.

Prospero, F. (2010). Healthy Open Spaces: A summary of the impact of open spaces on health and wellbeing. Lower Hutt: Regional Public Health .

RTPI. (2014, October). Promoting Healthy Cities. Retrieved from Royal Town Planning Institute: https://www.rtpi.org.uk/media/ I470/promoting-healthy-cities-full-report-20I4.pdf

Sandford, A. (2020, April 3). Coronavirus: Half of humanity now on lockdown as 90 countries call for confinement. Retrieved from Euronews: https://www.euronews.com/2020/04/02/coronavirus-ineurope-spain-s-death-toll-hits-10-000-after-record-950-new-deaths-in-24-hou

UN Women. (2020). Covid-I 9 and ensuring safe cities and safe public spaces for Women and Girls. Retrieved from UN Women: https://www.unwomen.org//media/headquarters/attachments/sections/library/publications/2020/brief-covid-19-andensuring-safe-cities-and-safe-public-spaces-for-women-and-girls-en.pdf?la=en\&vs $=632$

UNDESA (2014, July 10). World's population increasingly urban with more than half living in urban areas, Retrieved from United Nations:

http://www.un.org/en/development/desa/news/population/world-urbanization-prospects20l4.html

UN-Habitat. (2020). COVID-I 9 Response, Report of Activities. Nairobi: UN-Habitat.

UN-Habitat. (2020). UN-Habitat COVID-I 9 Response Plan. Nairobi: UN-Habitat.

UN-Habitat. (2020, June). UN-Habitat Guidance on COVID-1 9 and Public Space. Retrieved from UNHabitat: https://unhabitat.org/sites/default/files/2020/06/un-habitat_guidance_on_covid19_and_public_space.pdf

UN-HABITAT, UNCDF, UCLG-Africa, UNECA. (2020). COVID-I 9 IN AFRICAN CITIES: Impacts, Responses and Policies. Retrieved from United Nations Economic Comission for Africa: https://www.uneca.org/sites/default/files/PublicationFiles/covid19 in_african_cities_impacts_responses_and_policies2.pdf

UN-Habitat; UNDRR. (2020, June 15). Covid 19 demonstrates urgent need for cities to prepare for pandemics. Retrieved from United Nations Human Settlements Programme: https://unhabitat.org/opinion-covid-19-demonstrates-urgent-need-for-cities-to-prepare-forpandemics

United Nations. (2020). A UN framework for the immediate socioeconomic response to COVID-19. New York: United Nations.

United Nations. (2020, July no date). Policy Brief on COVID-19 in the Urban World. Retrieved from United Nations:

https://www.un.org/sites/un2.un.org/files/sg_policy_brief_covid_urban_world_july_2020.pdf

United Nations. (2020). United Nations Comprehensive Response to COVID-19. Saving Lives, Protecting societies, Recovering Better. New Work: United Nations.

WHO and UN-Habitat. (2020). Integrating health in urban and territorial planning: A sourcebook . Geneva: WHO. 